OPEN ACCESS

Edited by:

Tingyu $L i$,

Chongqing Medical University, China

Reviewed by:

Khaled Saad,

Assiut University Hospital, Egypt

Jorge Pérez-Gómez,

University of Extremadura, Spain

*Correspondence:

Feiyong Jia

jiafy@jlu.edu.cn

tThese authors have contributed equally to this work and share first authorship

Specialty section:

This article was submitted to Child and Adolescent Psychiatry,

a section of the journal

Frontiers in Pediatrics

Received: 01 November 2021 Accepted: 21 December 2021

Published: 13 January 2022

Citation:

Shan L, Dong H, Wang T, Feng J and Jia F (2022) Screen Time, Age and Sunshine Duration Rather Than Outdoor Activity Time Are Related to Nutritional Vitamin D Status in Children With ASD. Front. Pediatr. 9:806981. doi: 10.3389/fped.2021.806981

\section{Screen Time, Age and Sunshine Duration Rather Than Outdoor Activity Time Are Related to Nutritional Vitamin D Status in Children With ASD}

\author{
Ling Shan ${ }^{\dagger}$, Hanyu Dong ${ }^{\dagger}$, Tiantian Wang, Junyan Feng and Feiyong Jia* \\ Department of Developmental and Behavioral Pediatrics, The First Hospital of Jilin University, Changchun, China
}

Objective: This study aimed to investigate the possible association among vitamin $D$, screen time and other factors that might affect the concentration of vitamin $D$ in children with autism spectrum disorder (ASD).

Methods: In total, 306 children with ASD were recruited, and data, including their age, sex, height, weight, screen time, time of outdoor activity, ASD symptoms [including Autism Behavior Checklist (ABC), Childhood Autism Rating Scale (CARS) and Autism Diagnostic Observation Schedule-Second Edition (ADOS-2)] and vitamin D concentrations, were collected. A multiple linear regression model was used to analyze the factors related to the vitamin $D$ concentration.

Results: A multiple linear regression analysis showed that screen time $(\beta=-0.122, P$ $=0.032)$, age $(\beta=-0.233, P<0.001)$, and blood collection month (reflecting sunshine duration) ( $\beta=0.177, P=0.004$ ) were statistically significant. The vitamin $D$ concentration in the children with ASD was negatively correlated with screen time and age and positively correlated with sunshine duration.

Conclusion: The vitamin D levels in children with ASD are related to electronic screen time, age and sunshine duration. Since age and season are uncontrollable, identifying the length of screen time in children with ASD could provide a basis for the clinical management of their vitamin D nutritional status.

Keywords: autism spectrum disorder, sedentary behavior, multiple linear regression, environmental factor, 25(OH)D

\section{INTRODUCTION}

Autism spectrum disorder (ASD) is characterized in the Diagnostic and Statistical Manual of Mental Disorders-fifth edition (DSM-5) by persistent deficits in social interaction and communication and stereotyped or repetitive patterns of behavior, interests or activities (1). The latest ASD prevalence (2) reported by the U.S. Centers for Disease Control and Prevention (CDC) in 2020 was one in 54 children at the age of 8 years. Currently, ASD is a relatively common neurodevelopmental disorder in children that has a serious impact on children's social adaptability. Unfortunately, the etiology of ASD is unclear. Recent research $(3,4)$ has shown that ASD is the 
result of a combination of genetic and environmental factors. Environmental factors could include nutritional factors, heavy metal exposure, air pollution, socioeconomic factors (including lifestyles), etc. Vitamin D might be an environmental factor involved in $\operatorname{ASD}(5,6)$, and screen time has been proven to influence childhood development and social behaviors $(7,8)$.

Previous studies (9-11) have shown that the vitamin D levels in children with ASD are lower than those in typically developing children. Furthermore, there are negative correlations between the vitamin D levels and core symptoms of ASD (12). Moreover, vitamin D supplementation might improve the core symptoms of $\operatorname{ASD}(5,11,13)$. Skin under sun irradiation is a major source of vitamin $\mathrm{D}$ in vivo. Other factors (14) also affect the vitamin $\mathrm{D}$ concentrations, including genetic polymorphisms, age, geographical location and latitude, lifestyle (exposure behavior and culture), UVB dose, clothing and body surface area (BSA) exposure.

A sedentary lifestyle $(15,16)$ is an important cause of an insufficient vitamin D status. Zittermann (15) reported that adult male subjects with low levels of physical activity have lower blood vitamin D concentrations. Solis-Urra's study (16) showed that greater sedentary time is associated with vitamin $\mathrm{D}$ deficiency in adult and older women. Some studies have distinguished among various types of sedentary behavior $(17,18)$. Social activities, such as talking or hanging around, reading and playing musical instruments, are regarded as nonscreen-based sedentary behavior, whereas watching television (TV) and videos and playing traditional video games are regarded as screen-based sedentary behavior. Therefore, the use of electronic devices is an important aspect of sedentary behavior. Children with ASD could have longer screen times $(19,20)$. The latest World Health Organization (WHO) Guidelines (21) on Physical Activity and Sedentary Behavior released in 2020 suggested that children and adolescents should limit the amount of time spent being sedentary, particularly the amount of recreational screen time.

There have been limited studies concerning vitamin D levels and children's screen time. Soden and coworkers (22) showed that $\sim 54 \%$ of ASD children had insufficient serum 25-hydroxyvitamin D levels, and the mean electronic media use was $251 \mathrm{~min} /$ day; however, these authors did not consider the association between these two factors. Absoud's study (23) showed that vitamin D deficiency occurs in children (not ASD children) who exercised less outdoors, watched more TV, and were overweight. To date, no studies considered the relationship between the vitamin D levels and electronic screen time of ASD children. Based on the above studies, we hypothesize that the excessive screen time of children with ASD could be related to insufficient vitamin $\mathrm{D}$ concentrations due to decreased sun exposure because of less outdoor activity.

Our team conducted several preliminary studies investigating the relationship among $\mathrm{ASD}$, vitamin $\mathrm{D}(5,9,12)$ and the screen activities of children with $\operatorname{ASD}(7,8)$. Based on previous research, we conducted this study to explore the associations among vitamin $\mathrm{D}$, screen time and other factors that can affect the concentration of vitamin D in children with ASD, such as age, sunshine duration, Body Mass Index (BMI), and outdoor activity. This study aimed to further reveal the environmental factors of ASD and provide evidence for the clinical management of vitamin D levels in children with ASD.

\section{METHODS \\ Participants}

In total, 306 children diagnosed with ASD for the first time in the Department of Developmental and Behavioral Pediatrics of the First Hospital of Jilin University were recruited for this study. Recruitment started in March 2021 and was completed in August 2021. Inclusion criteria are as following. All children were from northeastern China $\left(38^{\circ} \mathrm{N}-53^{\circ} \mathrm{N}\right)$ with an age under 7 yearsold. The DSM-5 and Autism Diagnostic Observation ScheduleSecond Edition (ADOS-2) were utilized for the diagnosis of ASD. The participants were diagnosed for the first time and without systematic intervention. The Autism Behavior Checklist (ABC) and Childhood Autism Rating Scale (CARS) were also used to evaluate the symptoms of ASD to assist in the diagnosis of ASD. Exclusion criteria are: children with severe physical disabilities, uncontrolled epilepsy, vitamin D supplementation for the past 3 months, and clear metabolic diseases or genetic diseases. The study was approved by the ethics committee of our hospital, and informed consent was provided by the parents or caregivers of the children.

\section{Procedures}

We investigated the children's characteristics (age, sex, height, and weight), ASD symptoms, outdoor activity time, screen time and serum concentration of vitamin D. Height and weight were measured by physicians in the clinic. The parents provided the children's other basic characteristics and mean outdoor activity time per day when visiting the evaluator. The children's ASD symptoms were examined using the ABC and CARS. The ABC is a 57 -item screening checklist for autistic symptoms containing five subscales (body behavior, sensory, self-care, language and social interaction). This scale is designed for parent interviews. The CARS consists of 15 subscales, each of which is scored on a continuum from normal to severely abnormal. The CARS requires observation of the behavior of ASD children in a consulting room. The CARS was evaluated by experienced evaluators from our department. The evaluator also collected the screen time per day on weekdays and weekends and calculated and recorded the average daily screen time as follows: average daily screen time (hours) $=$ [screen time per day on weekdays $(\min )^{*} 5+$ screen time per day on weekends $\left.(\min )^{*} 2\right] / 7 / 60$. The ADOS-2 was utilized in this study as a diagnostic tool for ASD. The ADOS-2 (24) is a semistructured, standardized assessment tool for individuals with suspected ASD and measures autism symptoms in the domains of social relatedness, communication, play, and repetitive behaviors; the ADOS-2 is considered the gold standard for ASD diagnostic evaluation. We also tested the serum vitamin $\mathrm{D}$ concentration of the children with ASD. 25 -Hydroxyvitamin $\mathrm{D}(25(\mathrm{OH}) \mathrm{D})$ is the main circulating form of vitamin $\mathrm{D}$. Therefore, we measured the concentration of $25(\mathrm{OH}) \mathrm{D}$ to reflect the nutritional status of vitamin $\mathrm{D}$ in the children with ASD. All samples were tested by Guangzhou KingMed Diagnostics Group Co., Ltd. (KingMed Diagnostics, 
TABLE 1 | Patient characteristics.

\begin{tabular}{lc}
\hline & $\boldsymbol{N}=\mathbf{3 0 6}$ \\
\hline Age $(M \pm S D)($ years $)$ & $3.39 \pm 1.07$ \\
Vitamin $D(M \pm S D)(n g / m l)$ & $25.26 \pm 9.29$ \\
Screen time (M \pm SD) (hours) & $2.12 \pm 2.14$ \\
ABC $^{a}$ score ( $\left.M \pm S D\right)$ & $53.31 \pm 16.31$ \\
CARS $^{b}$ score $(M \pm S D)$ & $33.92 \pm 4.36$ \\
\hline
\end{tabular}

${ }^{a} A B C$, Autism Behavior Checklist.

${ }^{b}$ CARS, Childhood Autism Rating Scale.

SSE 603882) using the liquid chromatography tandem mass spectrometry method.

\section{Statistical Analysis}

We used Statistical Product and Service Solutions (SPSS) software version 23.0 (SPSS for Windows, SPSS Inc., Chicago, IL, USA) to analyze all data. The continuous variables with normal distributions are represented as the means \pm standard deviations (SDs), and the categorical variables are represented as frequencies (percentages). The continuous variables with normal distributions were compared by Student's $t$-test or ANOVA. The correlations among the serum concentration of vitamin $\mathrm{D}$, age, and screen time were detected by a Pearson's correlation test. A multiple linear regression model was used to analyze the factors related to the vitamin $\mathrm{D}$ concentrations. The results were considered significant at $P<0.05$.

\section{RESULTS}

The clinical and sociodemographic characteristics are presented in Table 1. There were 233 boys and 73 girls among the children with ASD (76.14 vs. 23.86\%). Their age ranged from 1.7 to 7 years old $(3.39 \pm 1.07 \mathrm{y})$. Their mean screen time was $2.12 \pm$ $2.14 \mathrm{~h}$ per day. The mean concentration of serum $25(\mathrm{OH}) \mathrm{D}$ was $25.26 \pm 9.29 \mathrm{ng} / \mathrm{ml}$. We grouped the ASD children according to sex, BMI, time of outdoor activities and blood collection month (reflecting the sunshine duration) and compared the vitamin $\mathrm{D}$ concentrations among the groups (Table 2). The vitamin $\mathrm{D}$ concentration was not statistically significant in the comparison between the male and female groups $(t=-0.537$, $P=0.591)$. We calculated the BMI of all enrolled children $\left(\mathrm{kg} / \mathrm{m}^{2}\right)$. According to their BMI (25), the children with ASD were divided into normal or underweight, overweight and obese groups. The comparison of the vitamin $\mathrm{D}$ levels among the groups was not statistically significant ( $F=1.441, P=0.239$ ). However, as the BMI increased, the vitamin D levels tended to decrease (Table 2). According to the time of outdoor activities per day, we divided the children into four groups ( $<30 \mathrm{~min}, \geq 30$ and $<60 \mathrm{~min}, \geq 60$ and $<90 \mathrm{~min}, \geq 90 \mathrm{~min}$ ). The comparison of the vitamin $\mathrm{D}$ levels among the groups was not statistically significant $(F=1.193, P=0.313)$. However, as the outdoor activity time increased, the vitamin D levels tended to increase (Table 2). According to the blood collection month, we divided the children into six groups (March, April, May, June, July, and August).
TABLE 2 | Comparison of vitamin D in each group (grouped by gender, BMl, time of outdoor activities and blood collection month).

\begin{tabular}{|c|c|c|c|c|}
\hline & $N(\%)$ & $\begin{array}{c}\text { Vitamin D } \\
(\mathrm{M} \pm \mathrm{SD}) \\
(\mathrm{ng} / \mathrm{ml})\end{array}$ & $t / F$ & $P$ \\
\hline Gender & & & -0.537 & 0.591 \\
\hline Male & $233(76.1)$ & $25.10 \pm 9.05$ & & \\
\hline Female & 73 (23.9) & $25.77 \pm 10.04$ & & \\
\hline $\mathrm{BMI}^{\mathrm{a}}$ & & & 1.441 & 0.239 \\
\hline Normal or underweight & 177 (61.0) & $25.87 \pm 9.48$ & & \\
\hline Overweight & $61(21.0)$ & $25.30 \pm 10.12$ & & \\
\hline Obese & $52(18.0)$ & $23.37 \pm 7.53$ & & \\
\hline Time of outdoor activities ${ }^{b}$ & & & 1.193 & 0.313 \\
\hline$<30 \mathrm{~min}$ & $89(29.6)$ & $24.20 \pm 10.14$ & & \\
\hline$\geq 30$ and $<60 \mathrm{~min}$ & $94(31.2)$ & $25.00 \pm 8.76$ & & \\
\hline$\geq 60$ and $<90 \mathrm{~min}$ & $53(17.6)$ & $25.81 \pm 8.15$ & & \\
\hline$\geq 90 \mathrm{~min}$ & $65(21.6)$ & $26.96 \pm 9.77$ & & \\
\hline Blood collection month & & & 2.728 & $0.020^{*}$ \\
\hline March & $100(32.7)$ & $22.86 \pm 8.98$ & & \\
\hline April & $80(26.1)$ & $24.98 \pm 11.38$ & & \\
\hline May & $36(11.8)$ & $26.89 \pm 9.61$ & & \\
\hline June & $46(15.0)$ & $27.24 \pm 7.67$ & & \\
\hline July & $26(8.5)$ & $27.95 \pm 4.87$ & & \\
\hline August & $18(5.9)$ & $27.64 \pm 5.36$ & & \\
\hline
\end{tabular}

a Body Mass Index (BMI) data were not available for 16 children.

${ }^{b}$ Time of outdoor activities data were not available for five children. ${ }^{\star} P<0.05$.

TABLE 3 | Correlations among vitamin D, age, and screen time.

\begin{tabular}{lcc}
\hline & $\boldsymbol{R}$ & $\boldsymbol{P}$ \\
\hline Age & -0.115 & $0.045^{\star}$ \\
Screen time & -0.272 & $<0.001^{*}$ \\
\hline
\end{tabular}

${ }^{\star} P<0.05$.

The comparison of the vitamin D levels among the groups was statistically significant $(F=2.728, P=0.020)$. It seems that the longer the sunshine duration, the higher the vitamin D concentration (Table 2). The correlation analysis showed that the vitamin $\mathrm{D}$ concentration of the children with ASD was negatively correlated with age $(r=-0.115, P=0.045)$ and screen time $(r=-0.272, P<0.001)$ (Table 3; Figures 1, 2). The older the age and the longer the screen time, the lower the vitamin $\mathrm{D}$ concentration.

We incorporated age, screen time, BMI, time of outdoor activity, and blood collection month into a multiple linear regression model (Table 4) with vitamin D as the dependent variable. We analyzed whether these factors were related to the vitamin D concentrations in the children with ASD. The results of the multiple linear regression showed that age $(\beta$ $=-0.233, P<0.001)$, screen time $(\beta=-0.122, P=$ $0.032)$ and blood collection month $(\beta=0.177, P=0.004)$ were related to the vitamin $\mathrm{D}$ concentrations in the children with ASD. 


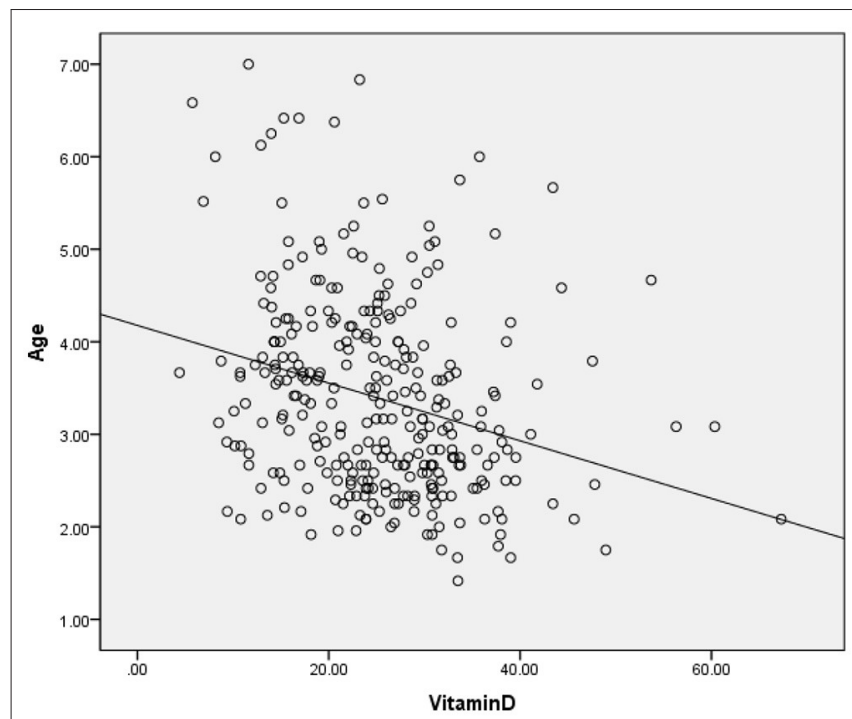

FIGURE 1 | Correlation of vitamin D (ng/ml) and age (y).

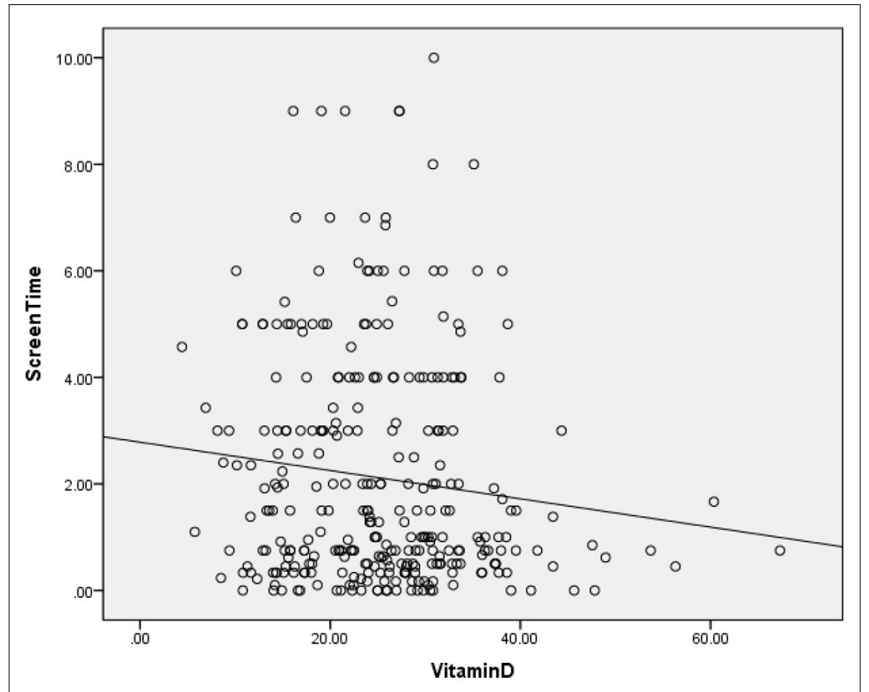

FIGURE 2 | Correlation of vitamin D (ng/ml) and screen time (h).

\section{DISCUSSION}

Our results suggest that the vitamin D concentrations in children with ASD are negatively correlated with screen time, and other factors that might be related to the vitamin $\mathrm{D}$ concentration include age and sunshine duration.

\section{Screen Time and Vitamin D}

Our results suggest that there is an association between screen time and the vitamin D concentrations in children with ASD. A study (26) based on adults suggested that screen time could be related to a lack of time for physical activity. A Brazilian study (27) involving 12- to 17-year-old adolescents also showed that they spend a significant amount of time each day in front of
TABLE 4 | Multiple linear regression model of vitamin D.

\begin{tabular}{lcccc}
\hline & $\boldsymbol{\beta}$ & $\mathbf{T}$ & $\mathbf{9 5 \%} \mathbf{C l}$ & $\mathbf{P}$ \\
\hline Age & -0.233 & -4.076 & $-0.260,-0.091$ & $<0.001^{*}$ \\
Screen time & -0.122 & -2.157 & $-0.017,-0.001$ & $0.032^{*}$ \\
Body Mass Index (BMI) & -0.059 & -1.038 & $-2.071,0.641$ & 0.300 \\
Time of outdoor activities & 0.014 & 0.235 & $-0.887,1.127$ & 0.814 \\
Blood collection month & 0.177 & 2.928 & $0.346,1.767$ & $0.004^{*}$ \\
\hline
\end{tabular}

${ }^{\star} P<0.05$.

electronic screens, while $~ 50 \%$ of teenagers do not engage in any physical activity in their spare time. Dong (28) conducted a study involving 559 adolescents aged 14 to 18 years in the southern USA and identified physical activity to be associated with the plasma 25(OH)D concentrations. Lenders (29) also reached a similar conclusion that physical activity was positively associated with the $25(\mathrm{OH}) \mathrm{D}$ levels, although the sample size was small. As mentioned earlier, we speculate that a very long screen time (as one of the most important sedentary behaviors of children) might affect children's outdoor activity time and further affect their vitamin D levels.

However, our results do not seem to fully support this speculation. Our results suggest that screen time is related to the vitamin $\mathrm{D}$ concentrations, but the outdoor activity time is not related to the vitamin $\mathrm{D}$ concentrations. Although our data show that vitamin D has a tendency to increase with increasing outdoor activity time, it is not statistically significant. According to a 2014 meta-analysis (30), sedentary behavior and physical activity were negatively correlated in young people, but the effect size was small, indicating that longer sedentary behavior cannot be completely equal to shorter activity times. Thus, sedentary behavior and less physical activity are different behaviors $(31,32)$, and their effects on the vitamin $\mathrm{D}$ concentrations cannot be substituted for each other. Inactivity and screen time might have distinct pathophysiological mechanisms and implications for illness (33). Our results suggest that screen time (but not outdoor time) is associated with the vitamin D levels, which is not ambivalent.

Another study showed a different result. A 2019 Brazilian study showed that moderate-to-vigorous physical activity could play an important role in increasing serum $25(\mathrm{OH}) \mathrm{D}$ concentrations in adolescence, especially in boys, regardless of the screen time. The sample size of the study was large $(n=$ 1,152 ), but the subjects were typically developing adolescents aged 12-17 years, who were much older than our participants. Since vitamin D in children with ASD might have different metabolic statuses (6) and related metabolic gene polymorphisms (34, 35) compared with typically developing children, the associations among screen time, sedentary behavior, outdoor activity time and vitamin $\mathrm{D}$ deserve further discussion.

\section{Age and Vitamin D}

Our results suggest that the age of children with ASD is negatively correlated with the vitamin D concentrations. Older children with ASD have lower vitamin D concentrations. Andiran's 
research (36) conducted correlation analyses in Turkey and revealed that the $25(\mathrm{OH}) \mathrm{D}$ levels were negatively correlated with age ( $0-5$ age group, $34.2 \pm 16.2 \mathrm{ng} / \mathrm{ml} ; 5-10$ age group, 20.5 $\pm 8.7 \mathrm{ng} / \mathrm{ml} ; 10-16$ age group, $18.7 \pm 11.5 \mathrm{ng} / \mathrm{ml})$. This finding is likely related to the preventive measures in primary health care implemented by the Ministry of Health in Turkey (36). Since 2005, vitamin D supplements have been distributed to all newborns throughout their infancy at no financial cost (37). A US survey (38) involving 4,558 children and adolescents aged 111 years also showed that the vitamin $\mathrm{D}$ concentration of the children aged 1-5 was higher than that of the children aged 61 (70 vs. $66 \mathrm{nmol} / \mathrm{L}$ ). However, the United States is a multiracial country, and non-Hispanic black and Hispanic children have the lowest levels of $25(\mathrm{OH}) \mathrm{D}$, which might have had an impact on the results.

The situation is different in China. Vitamin D is recommended for routine supplementation of 400-800 units from birth to early childhood (rather than school age), and it is not a free-cost drug in China. Universal primary health care for children must be further strengthened. Similarly, in the UK, a population-based study conducted in 2011 (23) also showed that the plasma vitamin D levels decreased progressively with age. Although there are no recommendations for vitamin D supplementation in older children, in younger children, the recommended supplement uptake is low. The participants in this study were all children who had not taken vitamin D regularly in the previous 3 months; thus, vitamin D supplements can be ignored. The reason for this phenomenon is not yet clear.

\section{Sunshine Duration and Vitamin D}

Our research suggests that the vitamin D levels in the summer (June-August) are higher than those in the spring (MarchMay). Most humans depend on sunlight exposure to satisfy their requirements for vitamin D (39). Solar ultraviolet B photons are absorbed by the skin, leading to the transformation of 7-dehydrocholesterol into vitamin D3 (cholecalciferol) (40). Vitamin D levels are related to ultraviolet light, which is easy to understand. Similarly, some studies (41-43) have shown that season is an important factor affecting the vitamin D status. The vitamin $\mathrm{D}$ levels in the human body are the highest in the summer (41).

Interestingly, regarding sunshine duration, June is the longest month of sunshine in the year, but the level of vitamin D in July and August is slightly higher than that in June, which seems to be a delayed phenomenon. There was indeed a Brazilian study that supports our speculation. In Brazil, the results of the São Paulo vitamin D evaluation study (44) showed that the lowest UV radiation levels were recorded in the winter, while the lowest $25(\mathrm{OH}) \mathrm{D}$ concentrations occurred in the spring, corresponding to a delay of a season. A strong correlation was observed between the current mean $25(\mathrm{OH}) \mathrm{D}$ concentration and the mean UVR value from the previous season $(r=0.98)$ (45).

\section{Possible Intervention Strategies}

We recommend limiting the screen time of children with ASD. Children younger than 2 years who have a deviation in social and language development but have not yet been confirmed with a diagnosis of ASD according to the AAP recommendation
(46) should avoid electronic screen devices. The limited screen time requires high-quality content, high-quality company and interaction with parents. In addition, it is still recommended that children with ASD take vitamin D while monitoring their vitamin D levels, especially those who are older and have longer screen times, during short sunshine duration seasons and in areas with high latitudes (low UV), emphasizing the management of multilevel related environmental factors, in addition to behavioral interventions and education for children with ASD. In the future, a cohort study will be performed to verify the effectiveness of our management strategy.

\section{Limitations and Further Directions}

We ignored the vitamin $\mathrm{D}$ intake in the diet. Although vitamin $\mathrm{D}$ produced through the skin is the most important source, under the condition of insufficient sunlight (especially in the spring at high latitudes in northeastern China), food can supply $\sim 10$ to $20 \%$ of vitamin D (39). Future research should consider dietary factors.

This study is only a cross-sectional study and cannot provide causal conclusions. Further prospective cohort studies are needed.

We only investigated the vitamin D levels of children with ASD in the spring and summer, while the sunshine duration is shorter in the autumn and winter. Therefore, we must conduct a whole year of research in the future to verify our conclusions.

\section{CONCLUSION}

The vitamin D levels in children with ASD are related to their electronic screen time, age and sunshine duration. While age and season are uncontrollable, identifying the length of screen time in children with ASD could provide a basis for the clinical management of their vitamin D levels.

\section{DATA AVAILABILITY STATEMENT}

The raw data supporting the conclusions of this article will be made available by the authors, without undue reservation.

\section{ETHICS STATEMENT}

The studies involving human participants were reviewed and approved by the Ethics Committee of the First Hospital of Jilin University. Written informed consent to participate in this study was provided by the participants' legal guardian/next of kin.

\section{AUTHOR CONTRIBUTIONS}

LS: methodology, investigation, and writing the initial manuscript. HD: methodology, investigation, formal analysis, and some writing. TW: data curation and formal analysis and editing the manuscript. JF: investigation, formal analysis, and editing the manuscript. FJ: conceptualization, funding acquisition, supervision, and oversight and resources. All authors contributed to the article and approved the submitted version. 


\section{FUNDING}

This work was supported by the National Natural Science Foundation of China (Grant Number: 81973054), Key Scientific and Technological Projects of Guangdong

\section{REFERENCES}

1. Battle DE. Diagnostic and statistical manual of mental disorders (DSM). CoDAS. (2013) 25:191-2. doi: 10.1590/s2317-17822013000200017

2. Maenner MJ, Shaw KA, Baio J, Washington A, Patrick M, DiRienzo $\mathrm{M}$, et al. Prevalence of autism spectrum disorder among children aged 8 years-autism and developmental disabilities monitoring network, 11 sites, United States, (2016). MMWR Surveill Summ. (2020) 69:1-12. doi: 10.15585/mmwr.ss6903al

3. Kim YS, Leventhal BL. Genetic epidemiology and insights into interactive genetic and environmental effects in autism spectrum disorders. Biol Psychiatry. (2015) 77:66-74. doi: 10.1016/j.biopsych.2014.11.001

4. Ramaswami G, Geschwind DH. Genetics of autism spectrum disorder. Handb Clin Neurol. (2018) 147:321-9. doi: 10.1016/B978-0-444-63233-3.00021-X

5. Feng J, Shan L, Du L, Wang B, Li H, Wang W, et al. Clinical improvement following vitamin D3 supplementation in autism spectrum disorder. Nutr Neurosci. (2017) 20:284-90. doi: 10.1080/1028415X.2015.1123847

6. Jia F, Shan L, Wang B, Li H, Miao C, Xu Z, et al. Bench to bedside review: possible role of vitamin D in autism spectrum disorder. Psychiatry Res. (2018) 260:360-5. doi: 10.1016/j.psychres.2017.12.005

7. Dong HY, Wang B, Li HH, Yue XJ, Jia FY. Correlation between screen time and autistic symptoms as well as development quotients in children with autism spectrum disorder. Front Psychiatry. (2021) 12:619994. doi: $10.3389 /$ fpsyt.2021.619994

8. Dong HY, Feng JY, Wang B, Shan L, Jia FY. Screen time and autism: current situation and risk factors for screen time among pre-school children with ASD. Front Psychiatry. (2021) 12:675902. doi: 10.3389/fpsyt.2021.675902

9. Wang T, Shan L, Du L, Feng J, Xu Z, Staal WG, et al. Serum concentration of 25-hydroxyvitamin $\mathrm{D}$ in autism spectrum disorder: a systematic review and meta-analysis. Eur Child Adolesc Psychiatry. (2016) 25:341-50. doi: 10.1007/s00787-015-0786-1

10. Sengenç E, Kiykim E, Saltik S. Vitamin D levels in children and adolescents with autism. J Int Med Res. (2020) 48:300060520934638. doi: 10.1177/0300060520934638

11. Saad K, Abdel-Rahman AA, Elserogy YM, Al-Atram AA, Cannell JJ, Bjørklund G, et al. Vitamin D status in autism spectrum disorders and the efficacy of vitamin D supplementation in autistic children. Nutr Neurosci. (2016) 19:346-51. doi: 10.1179/1476830515Y.0000000019

12. Dong HY, Wang B, Li HH, Shan L, Jia FY. [Correlation between serum 25-hydroxyvitamin D level and core symptoms of autism spectrum disorder in children]. Zhonghua $\mathrm{Er} \mathrm{Ke} Z \mathrm{Za}$ Zhi. (2017) 55:916-9. doi: 10.3760/cma.j.issn.0578-1310.2017.12.010

13. Saad K, Abdel-Rahman AA, Elserogy YM, Al-Atram AA, El-Houfey AA, Othman HA, et al. Randomized controlled trial of vitamin D supplementation in children with autism spectrum disorder. J Child Psychol Psychiatry. (2018) 59:20-9. doi: 10.1111/jcpp.12652

14. Saponaro F, Saba A, Zucchi R. An update on vitamin D metabolism. Int J Mol Sci. (2020) 21:6573. doi: 10.3390/ijms21186573

15. Zittermann A, Sabatschus O, Jantzen S, Platen P, Danz A, Dimitriou T, et al. Exercise-trained young men have higher calcium absorption rates and plasma calcitriol levels compared with age-matched sedentary controls. Calcif Tissue Int. (2000) 67:215-9. doi: 10.1007/s002230001132

16. Solis-Urra P, Cristi-Montero C, Romero-Parra J, Zavala-Crichton JP, SaezLara MJ, Plaza-Diaz J. Passive commuting and higher sedentary time is associated with vitamin D deficiency in adult and older women: results from Chilean national health survey 2016-2017. Nutrients. (2019) 11:300. doi: 10.3390/nu11020300

17. Winther A, Ahmed LA, Furberg AS, Grimnes G, Jorde R, Nilsen OA, et al. Leisure time computer use and adolescent bone health-findings from
Province (Grant Number: 2018B030335001), Joint Fund Bethune Medical Special Project of Jilin Province (Grant Number: 20200201507JC), and the Project of Jilin Provincial Department of Finance (Grant Number: 2018SCZWSZX-60). the Tromsø study, fit futures: a cross-sectional study. BMJ Open. (2015) 5:e06665. doi: 10.1136/bmjopen-2014-006665

18. Pate RR, Mitchell JA, Byun W, Dowda M. Sedentary behaviour in youth. $\mathrm{Br} J$ Sports Med. (2011) 45:906-13. doi: 10.1136/bjsports-2011-090192

19. Gwynette MF, Sidhu SS, Ceranoglu TA. Electronic screen media use in youth with autism spectrum disorder. Child Adolesc Psychiatr Clin N Am. (2018) 27:203-19. doi: 10.1016/j.chc.2017.11.013

20. Healy S, Haegele JA, Grenier M, Garcia JM. Physical activity, screentime behavior, and obesity among 13-year olds in Ireland with and without autism spectrum disorder. J Autism Dev Disord. (2017) 47:49-57. doi: 10.1007/s10803-016-2920-4

21. WHO Guidelines Approved by the Guidelines Review Committee. In: WHO Guidelines on Physical Activity and Sedentary Behaviour. edn. Geneva: World Health Organization (2020).

22. Soden SE, Garrison CB, Egan AM, Beckwith AM. Nutrition, physical activity, and bone mineral density in youth with autistic spectrum disorders. J Dev Behav Pediatr. (2012) 33:618-24. doi: 10.1097/DBP.0b013e318260943c

23. Absoud M, Cummins C, Lim MJ, Wassmer E, Shaw N. Prevalence and predictors of vitamin D insufficiency in children: a Great Britain population based study. PLoS ONE. (2011) 6:e22179. doi: 10.1371/journal.pone.0022179

24. Kamp-Becker I, Albertowski K, Becker J, Ghahreman M, Langmann A, Mingebach T, et al. Diagnostic accuracy of the ADOS and ADOS-2 in clinical practice. Eur Child Adolesc Psychiatry. (2018) 27:1193-207. doi: 10.1007/s00787-018-1143-y

25. Li H, Ji CY, Zong XN, Zhang YQ. [Body mass index growth curves for Chinese children and adolescents aged 0 to 18 years]. Zhonghua Er Ke Za Zhi. (2009) 47:493-8. doi: 10.3760/cma.j.jissn.0578-1310.2009.07.004

26. Jones SA, Wen F, Herring AH, Evenson KR. Correlates of US adult physical activity and sedentary behavior patterns. J Sci Med Sport. (2016) 19:1020-7. doi: 10.1016/j.jsams.2016.03.009

27. Schaan CW, Cureau FV, Bloch KV, de Carvalho KMB, Ekelund U, Schaan BD. Prevalence and correlates of screen time among Brazilian adolescents: findings from a country-wide survey. Appl Physiol Nutr Metab. (2018) 43:684-90. doi: 10.1139/apnm-2017-0630

28. Dong Y, Pollock N, Stallmann-Jorgensen IS, Gutin B, Lan L, Chen TC, et al. Low 25-hydroxyvitamin D levels in adolescents: race, season, adiposity, physical activity, and fitness. Pediatrics. (2010) 125:1104-11. doi: 10.1542/peds.2009-2055

29. Lenders CM, Feldman HA, Von Scheven E, Merewood A, Sweeney C, Wilson DM, et al. Relation of body fat indexes to vitamin D status and deficiency among obese adolescents. Am J Clin Nutr. (2009) 90:459-67. doi: $10.3945 /$ ajen.2008.27275

30. Pearson N, Braithwaite RE, Biddle SJ, van Sluijs EM, Atkin AJ. Associations between sedentary behaviour and physical activity in children and adolescents: a meta-analysis. Obes Rev. (2014) 15:666-75. doi: 10.1111/obr.12188

31. Ottevaere C, Huybrechts I, Benser J, De Bourdeaudhuij I, Cuenca-Garcia $\mathrm{M}$, Dallongeville J, et al. Clustering patterns of physical activity, sedentary and dietary behavior among European adolescents: the HELENA study. BMC Public Health. (2011) 11:328. doi: 10.1186/1471-2458-11-328

32. de Lucena JM, Cheng LA, Cavalcante TL, da Silva VA, de Farias Júnior JC. [Prevalence of excessive screen time and associated factors in adolescents]. Rev Paul Pediatr. (2015) 33:407-14. doi: 10.1016/j.rppede.2015. 08.014

33. da Silva ACM, Cureau FV, de Oliveira CL, Giannini DT, Bloch KV, Kuschnir MCC, et al. Physical activity but not sedentary time is associated with vitamin $\mathrm{D}$ status in adolescents: study of cardiovascular risk in adolescents (ERICA). Eur J Clin Nutr. (2019) 73:432-40. doi: 10.1038/s41430-018-0192-0

34. Mobasheri L, Moossavi SZ, Esmaeili A, Mohammadoo-Khorasani M, Sarab GA. Association between vitamin D receptor gene FokI and TaqI variants with 
autism spectrum disorder predisposition in Iranian population. Gene. (2020) 723:144133. doi: 10.1016/j.gene.2019.144133

35. Guerini FR, Bolognesi E, Chiappedi M, Mensi MM, Fumagalli O, Rogantini C, et al. Vitamin D receptor polymorphisms associated with autism spectrum disorder. Autism Res. (2020) 13:680-90. doi: 10.1002/aur.2279

36. Andiran N, Çelik N, Akça H, Dogan G. Vitamin D deficiency in children and adolescents. J Clin Res Pediatr Endocrinol. (2012) 4:25-9. doi: $10.4274 /$ jcrpe. 574

37. Hatun S, Bereket A, Ozkan B, Coşkun T, Köse R, Calýkoglu AS. Free vitamin D supplementation for every infant in Turkey. Arch Dis Child. (2007) 92:373-4. doi: 10.1136/adc.2006.113829

38. Mansbach JM, Ginde AA, Camargo CA Jr. Serum 25-hydroxyvitamin D levels among US children aged 1 to 11 years: do children need more vitamin D? Pediatrics. (2009) 124:1404-10. doi: 10.1542/peds.2008-2041

39. Schramm S, Lahner H, Jöckel KH, Erbel R, Führer D, Moebus S. Impact of season and different vitamin D thresholds on prevalence of vitamin D deficiency in epidemiological cohorts-a note of caution. Endocrine. (2017) 56:658-66. doi: 10.1007/s12020-017-1292-7

40. Bandeira F, Griz L, Dreyer P, Eufrazino C, Bandeira C, Freese E. Vitamin D deficiency: a global perspective. Arq Bras Endocrinol Metabol. (2006) 50:6406. doi: 10.1590/S0004-27302006000400009

41. Valtueña J, Breidenassel C, Folle J, González-Gross M. Retinol, $\beta$-carotene, $\alpha$ tocopherol and vitamin D status in European adolescents; regional differences an variability: a review. Nutr Hosp. (2011) 26:280-8.

42. Cranney A, Weiler HA, O’Donnell S, Puil L. Summary of evidence-based review on vitamin D efficacy and safety in relation to bone health. Am J Clin Nutr. (2008) 88:513s-9s. doi: 10.1093/ajcn/88.2.513S

43. Karacan M, Usta A, Biçer S, Baktir G, Ipek Gündogan G, Sancakli Usta C, et al. Serum vitamin D levels in healthy urban population at reproductive age: effects of age, gender and season. Cent Eur J Public Health. (2020) 28:306-12. doi: 10.21101/cejph.a5947
44. Maeda SS, Saraiva GL, Hayashi LF, Cendoroglo MS, Ramos LR, Corrêa Mde P, et al. Seasonal variation in the serum 25-hydroxyvitamin D levels of young and elderly active and inactive adults in São Paulo, Brazil: the São PAulo vitamin D evaluation study (SPADES). Dermatoendocrinol. (2013) 5:211-7. doi: $10.4161 /$ derm. 24476

45. Saraiva GL, Cendoroglo MS, Ramos LR, Araújo LM, Vieira JG, Kunii I, et al. Influence of ultraviolet radiation on the production of 25 hydroxyvitamin $\mathrm{D}$ in the elderly population in the city of São Paulo (23 degrees 34'S), Brazil. Osteoporos Int. (2005) 16:1649-54. doi: 10.1007/s00198-0051895-3

46. Media and Young Minds. Pediatrics. (2016) 138:e20162591. doi: 10.1542/peds.2016-2591

Conflict of Interest: The authors declare that the research was conducted in the absence of any commercial or financial relationships that could be construed as a potential conflict of interest.

Publisher's Note: All claims expressed in this article are solely those of the authors and do not necessarily represent those of their affiliated organizations, or those of the publisher, the editors and the reviewers. Any product that may be evaluated in this article, or claim that may be made by its manufacturer, is not guaranteed or endorsed by the publisher.

Copyright (c) 2022 Shan, Dong, Wang, Feng and Jia. This is an open-access article distributed under the terms of the Creative Commons Attribution License (CC BY). The use, distribution or reproduction in other forums is permitted, provided the original author(s) and the copyright owner(s) are credited and that the original publication in this journal is cited, in accordance with accepted academic practice. No use, distribution or reproduction is permitted which does not comply with these terms. 